\title{
Munir Bashir: Mesopotamia
}

\section{René Van Peer}

Traducteur : Inge Sjollema

\section{OpenEdition}

\section{Journals}

Édition électronique

URL : http://journals.openedition.org/ethnomusicologie/551

ISSN : 2235-7688

\section{Éditeur}

ADEM - Ateliers d'ethnomusicologie

\section{Édition imprimée}

Date de publication : 1 janvier 2004

Pagination : 383-384

ISBN : 2-8257-0910-7

ISSN : 1662-372X

\section{Référence électronique}

René Van Peer, « Munir Bashir: Mesopotamia », Cahiers d'ethnomusicologie [En ligne], 17 | 2004, mis en ligne le 13 janvier 2012, consulté le 22 avril 2019. URL : http://journals.openedition.org/ ethnomusicologie/551

Ce document a été généré automatiquement le 22 avril 2019

Tous droits réservés 


\title{
Munir Bashir: Mesopotamia
}

\author{
René Van Peer \\ Traduction : Inge Sjollema
}

\section{RÉFÉRENCE}

Munir Bashir: Mesopotamia, 2 CD Le Chant du Monde 574 1255.56, 2004

\section{NOTE DE L'ÉDITEUR}

Traduit du néerlandais par Inge Sjollema

1 Au moment où j'écris ces lignes, l'Irak est en plein conflit, et nul ne sait ce qu'il en sera lorsqu'elles parviendront entre les mains du lecteur. La situation n'aura-t-elle fait qu'empirer, ou y aura-t-il entre temps eu une amélioration radicale, qui rendrait ce commentaire dépassé ?

Quoi qu'il en soit, avec toutes les émotions ressenties face aux crimes sans cesse commis, on en vient presque à oublier que cette région a été le berceau de la civilisation, que la Mésopotamie et Bagdad ont joué un rôle prépondérant dans l'histoire du monde. C'est là que la culture humaine a connu des jours de gloire dont les traces ont enorgueilli les siècles. Des choses indécentes s'y sont certes toujours passées; l'impression conservée est cependant celle des splendeurs et des acquisitions incomparables laissées par ce pays dans le domaine des arts et des sciences.

3 Mais la grandeur de l'Irak n'appartient pas qu'au lointain passé. Preuve en est la musique de Munir Bashir, joueur de oud décédé il y a sept ans. Bashir jouait comme s'il disposait de l'éternité. Pendant longtemps, le rôle du oud (al-'ûd est aussi l'ancêtre du luth européen) est demeuré secondaire dans la musique arabe; il se bornait à être l'instrument de prédilection pour accompagner le chant. Bashir est l'un des premiers à lui avoir redonné une place centrale. Seul sur scène, il naviguait avec son instrument vers les mers 
profondes et insondables de son âme, se laissant propulser par les courants qu'il rencontrait sur son chemin. Parfois calme, presque immobile, puis reparti à toute allure, culbutant, plongeant dans des directions imprévisibles, comme un oiseau qui a la voûte céleste à disposition, à dix milles lieues du monde.

4 Ses voyages, Munir Bashir les fit dans l'univers du maqâm, un système musical répandu dans l'ensemble du monde islamique, et qui fonctionne un peu comme celui de l'Inde, avec différentes échelles musicales admises et d'autres qu'il est préférable d'éviter. Parfois des mélodies définies servaient de point de départ à ses vagabondages. Cependant, le plus souvent, il commençait avec quelques notes du mode choisi, qui suffisaient à lui tracer son chemin. En route, ses pensées déterminaient sa destination, et ses éventuelles étapes intermédiaires se profilaient. Il lui arrivait aussi de s'arrêter face à un paysage qui l'émerveillait ou en un lieu qui l'inspirait particulièrement.

5 La musique est volatile, et celle que jouait Munir Bashir plus que toute autre; comme si les formes lui tombaient du ciel, invisibles et inaudibles jusqu'à ce qu'elles se transforment en son. Même si sa musique existait essentiellement par les fulgurances qui la traversaient en certains moments, il en reste heureusement des traces. Bien que son âme ne crée plus de nouvelles formes, elle est toujours vivante dans ses enregistrements. Ainsi ce magnifique double $\mathrm{CD}$ récemment paru, dont la musique a été enregistrée par Munir dans son propre studio en 1987, dix ans avant sa mort. Il avait tout son temps et il l'a pris. Un des morceaux dure ainsi plus d'une demi-heure. Il vous embarque dans ces échappées, dans ces lieux d'une beauté indescriptible qu'offrait son être le plus intime.

Quand vous lirez ceci, le monde aura peut-être déjà oublié l'Irak, comme il a oublié l'Afghanistan. Si c'était le cas, je voudrais ici vous rappeler ce pays. Sans aucun doute il existera encore, et la question sera de savoir si, pour ses habitants, la situation se sera améliorée. J'aimerais alors que l'on puisse penser à l'Irak comme à une terre d'où émane la beauté, la terre que Munir Bashir a fait renaître. 